\title{
Early postoperative complications in lung transplant recipients
}

\author{
Vanessa Soetanto ${ }^{1} \cdot$ Udhayvir Singh Grewal $^{2} \cdot$ Atul C. Mehta $^{3} \cdot$ Parth Shah $^{4} \cdot$ Manu Varma $^{5}$ - Delyse Garg ${ }^{6}$.

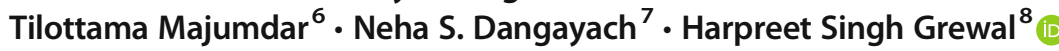

Received: 20 December 2020 /Revised: 8 March 2021 / Accepted: 10 March 2021 / Published online: 9 June 2021

(C) Indian Association of Cardiovascular-Thoracic Surgeons 2021

\begin{abstract}
Lung transplantation has become an established therapy for end-stage lung diseases. Early postoperative complications can impact immediate, mid-term, and long-term outcomes. Appropriate management, prevention, and early detection of these early postoperative complications can improve the overall transplant course. In this review, we highlight the incidence, detection, and management of these early postoperative complications in lung transplant recipients.
\end{abstract}

Keywords Lung transplantation $\cdot$ Complications $\cdot$ Postoperative

\section{Introduction}

Lung transplantation has become an established therapy for progressive end-stage lung diseases refractory to maximal medical management. The immediate post-transplantation phase is crucial in determining short- and long-term survival and, ultimately, the quality of life of a lung transplant recipient. We continue to learn the risk factors and strategies to mitigate postoperative complications. Here, we present a

Harpreet Singh Grewal

harpreetgrewa106@gmail.com

1 Department of Medicine, Rutgers New Jersey Medical School, Newark, NJ, USA

2 Department of Medicine, Louisiana State University Health Sciences Center, Shreveport, LA, USA

3 Respiratory Institute, Cleveland Clinic, Cleveland, OH, USA

4 Department of Medicine, Trumbull Regional Medical Center, Northeast Ohio Medical University, Warren, OH, USA

5 Division of Pediatric Cardiology, University of Texas Health Science Center at Houston, Houston, TX, USA

6 Division of Pulmonary and Critical Care Medicine, Newark Beth Israel Medical Center, Newark, NJ, USA

7 Department of Neurosurgery, Division of NeuroCritical Care, Icahn School of Medicine at Mount Sinai, New York, NY, USA

8 Department of Medicine, Division of Pulmonary, Allergy, and Critical Care Medicine Lung Transplantation, NewYork-Presbyterian/Columbia University Medical Center, New York, NY, USA concise review on the diagnosis and management of medical and surgical complications in the postoperative period, with major complications summarized in Table 1.

\section{Primary graft dysfunction}

Primary graft dysfunction (PGD) can be seen immediately after reperfusion of the allograft lung and affects $10-25 \%$ of lung transplant recipients [1]. It is caused by prolonged ischemia time, reperfusion injury, and increased immunologic response from the innate immune pathway $[2,3]$. Use of cardiopulmonary bypass (CPB) and single lung transplants have higher incidence of PGD [4]. Presence of fat embolism and thromboembolism increases the risk of PGD development by 25- and 5-fold respectively [5]. Risks are increased when donors are older, female, African American, have more than 20year smoking history, and have high fraction of inspired oxygen (FiO2) requirements [2]. Recipients with obesity, preoperative sarcoidosis, pulmonary artery hypertension, and excessive blood transfusion perioperatively are at higher risk of developing PGD [2].

The International Society for Heart and Lung Transplantation (ISHLT) 2016 consensus group statement suggests a severity grading system of PGD based on the onset of changes in partial pressure of oxygen $(\mathrm{PaO} 2) / \mathrm{FiO} 2$ ratio and chest radiography at 24,48 , and $72 \mathrm{~h}$ after reperfusion (Table 2) $[1,2,6]$. A grade 3 PGD designation $(\mathrm{PaO} 2 / \mathrm{FiO} 2$ ratio $<200$ or $\mathrm{SpO} 2 / \mathrm{FiO} 2$ ratio $<235$, and diffuse allograft 
Table 1 Summary of major complications after lung transplant

\begin{tabular}{ll}
\hline Complications $\quad$ Incidence & $\begin{array}{l}\text { Time of Management } \\
\text { onset post- } \\
\text { transplant }\end{array}$ \\
\hline
\end{tabular}

Primary graft dysfunction

$10-25 \%$

Rejection

Acute cellular rejection

Antibody-mediated rejection

Infection

Varies

Donor-derived pathogens (MRSA, Pseudomonas,

Enterobacter, MDRO)

Cytomegalovirus

Fungal (Candida, Aspergillus, Cryptococcus neoformans, endemic mycosis, mucormycosis, Scedosporium, Fusarium)

Invasive Aspergillus

Clostridium difficile

Pleural complications

\section{Hemothorax \\ Empyema \\ Airway complications \\ Bronchial stenosis \\ Bronchial dehiscence}

Hematologic

Thromboembolism

Bleeding

Pulmonary vascular stenosis

Diaphragm dysfunction

Renal dysfunction

Acute kidney injury

Neurologic

Stroke

Metabolic encephalopathy

Posterior reversible encephalopathy

\section{Seizure}

Cardiovascular

Within $72 \mathrm{~h}$ Lung-protective ventilation; restrictive fluid management; inhaled nitric oxide; ECMO initiation within $24 \mathrm{~h}$ of transplantation; empiric antimicrobials; immunosuppression; supportive [2]

\section{2-34\%}

12-18\%

3-8\%

15-20\%

5-45\%

$1.8-5.2 \%$

$3.2-8.2 \%$

64.5-68.8\%

$9.2 \%$

$41 \%$ of all neurological complications

$37 \%$ of all neurological complications

Rare Highest in
the first
year Immediate and onwards

Antimicrobials; perioperative antibiotic prophylaxis based on donor lung microbiology; CMV prophylaxis in the case of all but $\mathrm{D}-/ \mathrm{R}-$ cases; possible surgical intervention in severe cases of invasive species leading to dehiscence

Glucocorticoids; antithymocyte globulin; alemtuzumab; total lymphoid radiation; extracorporeal photopheresis [47]

Intravenous immunoglobulin; plasmapheresis; rituximab; proteasome inhibitors [49]
Immediate and onwards

Blood transfusions; surgical re-exploration if severe

Antimicrobial agents; chest tube
Within 9 months Within 5 weeks

Balloon bronchoplasty; stent placement [11-18]

Radiofrequency ablation [19]

Immediate

Immediate

Within

9 days

Immediate

Within

2 weeks

Standard stroke care including transesophageal

echocardiography and secondary stroke prevention [92-94]

Re-exploration for source of bleeding, supportive

Stent angioplasty, surgical intervention, re-transplantation [21, 24]

Supportive measures including non-invasive ventilation [27]

Supportive care; dialysis

Immediate

Identify and treat underlying causes, dialysis, reduction of immunosuppression, protein restriction, empiric fluoroquinolone, or macrolide if caused by hyperammonemia $[90,92]$

Discontinuation of calcineurin inhibitor; strict blood pressure control [95]

Antiepileptics; correction of underlying etiology [97] 
Table 1 (continued)

\begin{tabular}{llll}
\hline Complications & Incidence & $\begin{array}{l}\text { Time of } \\
\text { onset post- } \\
\text { transplant }\end{array}$ & Management \\
\hline Arrhythmia & $25-35 \%$ & 2 days & $\begin{array}{c}\text { Rate control and anti-arrhythmic agents with specialist consul- } \\
\text { tation; emergent cardioversion if hemodynamically unstable } \\
\text { [111] } \\
\text { Vasoplegia }\end{array}$ \\
\hline
\end{tabular}

infiltration on chest radiography) at $72 \mathrm{~h}$ after transplant is an ominous sign for short- and long-term outcomes, and is associated with a 30 -day mortality as high as $50 \%[1,7]$. Clinical signs of PGD include increased pulmonary vessel resistance, decreased compliance of the lungs, and formation of intrapulmonary shunts [2]. Limiting the length of cold ischemia, extending reperfusion time, and lung protective ventilation could help mitigate the development of PGD. Use of inhaled nitric oxide aids in the correction of oxygenation and ventilation-perfusion (V/Q) mismatch, while decreasing pulmonary artery pressure [2]. Extracorporeal membrane oxygenation (ECMO) can be lifesaving, improving survival by $50-80 \%$ [2], with expected survival to hospital discharge of $40-70 \%$ [8], 30-day survival of $82 \%$, and a 1-year survival of $64 \%$ [9]. Maximal benefit is achieved when ECMO is implemented within $24 \mathrm{~h}$ post-transplant, with less benefits if instituted after 24 to $48 \mathrm{~h}$ post-transplant [10]. It is generally indicated when there is inadequate oxygenation through ventilator support requiring $60 \% \mathrm{FiO} 2$ or higher, or when ventilator requirements reach a peak inspiratory pressure of 35 centimeters of water ( $\mathrm{cmH} 2 \mathrm{O})$ with the goal of reducing oxidative stress and barotrauma to the allograft [9]. There are, however, no specific indications for use of ECMO post-transplant, and should be decided on a case-by-case basis. Supportive management remains the cornerstone for managing severe PGD.

\section{Airway complications}

There are 6 categories of airway complications post-lung transplantation: bronchial stenosis, bronchial dehiscence, exophytic excessive granulation tissue formation, tracheo-bronchomalacia, bronchial fistulas, and endobronchial infections [11]. Incidence of airway complications has been reported to be 15-20\% of lung transplant recipients $[12,13]$, possibly due to ischemia of the donor bronchus [14]. Most complications occur after tissue remodeling and healing has taken place, but bronchial necrosis and dehiscence can present in the first 1 to 5 weeks, with an incidence of $1-10 \%$ [11]. Bronchial stenosis is the most common form of airway complication, presenting at around 2-9 months posttransplant, with a reported incidence of $1.6-32 \%$ [15]. It may be related to tracheo-bronchomalacia if there is $50 \%$ or greater narrowing of the airway lumen on expiration [15]. Balloon bronchoplasty is suggested for first-line therapy [11, 16]. Stent placement is used for severe bronchial stenosis with high complication rate from 48 to $75 \%$, though with comparable survival rates to those without airway complications [17]. A study by $\mathrm{Ma}$ et al. reported that forced expiratory volume in $1 \mathrm{~s}$ (FEV1) may only improve in patients who could undergo stent placement, and ultimately can tolerate stent removal [18]. Various treatment strategies have been reported including radiofrequency ablation in airway dehiscence [19], single running suture technique to mitigate anastomotic complications [20], laser photoresection, and bronchial artery revascularization, with variable success [15].

\section{Vascular complications}

Incidence of vascular anastomotic complications ranges from 1.8 to $5.2 \%[21,22]$ with higher incidence of pulmonary artery stenosis compared to pulmonary venous stenosis due to surgical technique and orientation of donor and recipient vasculature. It can present with non-specific symptoms including cough, dyspnea, pulmonary edema, hypoxia, and a need for mechanical ventilation. Mean time to diagnosis has been reported to be 9 days. Different imaging modalities including contrastenhanced computed tomography (CT), echocardiography, magnetic resonance imaging (MRI), V/Q scans, and intraoperative ultrasound have been used for diagnosis of vascular complications [21]. There are 5 types of vascular complications: kinking due to excessive length of donor and recipient vasculature and misalignment, transposition of donor vessel, stricture of anastomosis from overtightening or misalignment of suture line, obstruction from thrombosis or dissection, and extra luminal mass

Table 22016 International Society for Heart and Lung Transplantation primary graft dysfunction definition

\begin{tabular}{lll}
\hline Grade & Pulmonary edema on chest radiograph & $\mathrm{PaO} 2 / \mathrm{FiO} 2$ ratio \\
\hline 0 & No & $>300$ \\
1 & Yes & $>300$ \\
2 & Yes & 200 to 300 \\
3 & Yes & $<200$ \\
\hline
\end{tabular}

$\mathrm{PaO} 2$ serum partial pressure of oxygen, $\mathrm{FiO} 2$ fraction of inspired oxygen 
effect. Pulmonary artery stenosis is defined as anastomotic diameter of less than $75 \%$ compared to surrounding vessels [23]. Pulmonary vascular stenosis is rare and usually occurs in the first $48 \mathrm{~h}$ after lung transplantation [21]. In severe cases, endovascular intervention including thrombectomy, stent angioplasty [24], repeat surgery, re-transplantation, or lobectomy may be required.

\section{Diaphragm injury}

Diaphragm dysfunction can occur during lung transplant secondary to phrenic nerve injury. Several retrospective studies report a $3.2-8.2 \%$ incidence of diaphragmatic paralysis [25-27]. Diaphragmatic dysfunction could be further characterized by decreased force and electrical activity caused by slowed phrenic nerve conduction from myelin dysfunction, and weakness [28]. Diaphragm electromyography has been used in assessing the degree of diaphragm dysfunction [29]. Spontaneous diaphragm rupture has also been reported [30]. Prolonged CPB use, prior cardiothoracic surgery, and prior ECMO increase the risk of severe diaphragm dysfunction [27]. Consequences of diaphragmatic injury include longer duration of mechanical ventilation time and prolonged intensive care unit (ICU) stay. A large single-center study demonstrated that diaphragmatic injury is related to increase in PGD, decrease in survival, and increase in mortality [27]. Diaphragmatic paresis can ultimately recover with time and supportive measures with non-invasive ventilation if needed are the mainstay therapy for those with carbon dioxide retention.

\section{Pleural complications}

The incidence of pleural complications following lung transplant is $22-34 \%$ [31, 32]. They include hemothorax, chylothorax, pneumothorax, empyema, and air leaks. Uncomplicated effusions occur in all cases and are ipsilateral to the transplanted lung [31]. Uncomplicated effusions usually resolve within 2 weeks [33, 34]. Complicated effusions are associated with poor patient outcomes [31, 32, 35] and occur more commonly in double lung transplant recipients [32]. The incidence of hemothorax is between 12 and $18 \%$ with a trend towards increase in sarcoidosis and re-transplantations [31, 36, 37]. Morbidity and mortality are related to hemodynamic instability, need for vasopressor use, and surgical reexploration in up to $46-65 \%$ of cases $[31,37]$. Patients have longer ICU and hospital length of stay, decreased ventilatorfree days, decreased 30- and 90-day survival, but similar 1-, 3 -, and 5-year survival [37, 38].

Chylothorax occurs due to interruption of the thoracic duct and leakage of chyle into the pleural space. In a case series, 7 of $504(1.38 \%)$ patients developed chylothorax, 5 of which had underlying pulmonary fibrosis [35]. Dietary modifications with low-fat, medium-chain-triglyceride diet or total parenteral nutrition along with chest tube drainage and octreotide were insufficient for treatment and most required surgical intervention [35].

Incidence of empyema ranges from 3 to $8 \%$ [31, 32, 39, 40]. There is no difference between single and double lung transplant recipients, and no increased risk due to differences in demographics [39, 40]. Recognition is difficult due to blunted clinical manifestations in immunosuppressed patients $[33,40]$. Causative organisms range from gram-negative bacteria $(25 \%)$ to fungi $(61 \%)$, most commonly Candida albicans. Infections are monomicrobial in $71.4 \%$ of cases and polymicrobial in $14.3 \%$. In $14.3 \%$ of cases, no causative organism is identified [33, 39, 40]. Empyema causes increased morbidity and mortality in lung transplant recipients. In one study, 2 out of 3 patients with empyema died [31]. Herridge et al. reported that 7 of 30 patients with para-pneumonic effusion developed empyema, and 3 of those 7 died from septic shock [32]. Another study reported a mortality rate of $28.6 \%$ [39]. Wahidi et al. reported an overall 1-year survival rate post-lung transplant of $87 \%$, with a statistically significant lower survival rate of $67 \%$ if empyema occurred [40]. Cystic fibrosis has not been shown to have an increased rate of development of postoperative empyema [39].

\section{Air leaks and pneumothorax}

Air leaks and pneumothorax can occur due to donor-recipient size mismatch, bronchopleural fistulas, dehiscence of bronchial anastomoses, infection, rejection, or ischemia [31-34]. Herridge et al. reported 14 pneumothoraces out of 138 patients [32]; Ferrer et al. reported 8 out of 100 patients [31]. Two of the patients died, one due to anastomotic rupture, one due to Aspergillus infection from a concomitant air leak [41]. Air leaks can be transient or persistent if they last longer than 7 days. The prevalence of prolonged air leak ranges from 1 to $10 \%[31,32]$. In a series by Ferrer et al., 10 out of 100 patients had persistent air leak, of which 7 had undergone bilateral lung transplant. Five of 7 died in the postoperative period. Among the 5 who survived, 3 air leaks resolved spontaneously and 2 required operative intervention [31].

\section{Rejection}

Incidence of acute rejection in the first year has decreased from $55 \%$ to $17-28 \%$ [42-44]. Though rarely the cause of death, acute rejection is the greatest risk factor for development of chronic rejection, limiting median post-transplant survival to about 6 years [44]. Mangi et al. showed that acute rejection was most common and severe $(54 \% \geq \mathrm{A} 1)$ in the first 2 months. Young age, blunt trauma, non-black race, class II 
panel-reactive antibody (PRA) exceeding 10\%, human leukocyte antigen (HLA) mismatch at the DR locus, and use of nonO blood-group donors were associated with increased rate of rejection [45]. Increased incidence is also seen after infections with human influenza A, respiratory syncytial virus, rhinovirus, coronavirus, parainfluenza, and human metapneumovirus [46]. Grade A2 acute cellular rejection or higher is treated with pulse steroids. Persistent or refractory rejection can be treated with additional intravenous glucocorticoids, antithymocyte globulin, alemtuzumab, total lymphoid radiation, and extracorporeal photopheresis [47].

Diagnostic criteria for antibody-mediated rejection (AMR) were newly established in 2016. It is diagnosed when there is presence of antibodies against donor HLA seen on lung biopsy of the lung allograft, with or without the presence of complement $4 \mathrm{~d}$ within the graft [48]. Importantly, AMR may be clinical (dysfunction of the allograft without symptoms) or sub-clinical (normal allograft function) [48]. True incidence and prevalence of AMR are unknown as its diagnostic criteria have only recently been standardized. Witt et al. found 21 cases of AMR among 501 lung transplant recipients. Median time to development was 258 days after transplantation; 7 recipients developed AMR within 45 days. Fifteen patients improved and survived to hospital discharge; 5 died of refractory AMR. One survivor had bronchiolitis obliterans syndrome (BOS) at the time of AMR diagnosis, and the other 14 developed it during follow-up. Median survival after AMR diagnosis was 593 days [49].

Treatment for AMR includes administration of intravenous immunoglobulin (IVIG), plasmapheresis, and rituximab alone or in combination. Proteasome inhibitors like carfilzomib or bortezomib have been used, as well as eculizumab, an antibody targeting the $\mathrm{C} 5$ complement protein. Data is lacking regarding the best combination strategies in management of AMR $[49,50]$.

\section{Infection}

Infections account for significant morbidity and mortality in lung transplant recipients leading to accelerated graft failure. Risk factors for infectious complications include prolonged illness, organ dysfunction, immunosuppression, antimicrobial use, and poor nutritional state [51].

In the immediate postoperative period, donor-derived pathogens account for most infections and include community- and hospital-acquired pathogens like methicillin-resistant Staphylococcus aureus (MRSA), Pseudomonas, Enterobacter, and multidrug-resistant bacteria. Bacterial infections can present as pneumonia, para-pneumonic effusions, mediastinitis, empyema, cholangitis, anastomotic leaks, catheter-associated infections, and surgical wound dehiscence. Rapid diagnosis is warranted to identify source and pathogens to minimize drug toxicity and prolonged antimicrobial use. Meticulous attention is required to identify the source as features of sepsis may be absent and timely surgical interventions are critical.

Cytomegalovirus (CMV) infections most commonly occur in the first 6 months after transplant without prophylactic therapy. The greatest risk for primary infection is seronegative recipients of seropositive organs with up to $91.9 \%$ incidence of viremia and $50-65 \%$ of symptomatic infections by 90 days [52]. Lung recipients (D+ or $\mathrm{R}+$ ) are at high risk for viral reactivation and for adverse effects of CMV infection [53]. Though many viremic infections remain asymptomatic, organ manifestations include pneumonitis, hepatitis, pancolitis with ulceration, and less commonly retinitis and encephalitis.

Common fungal pathogens seen in transplant recipients include Candida, Aspergillus, Cryptococcus neoformans, and endemic mycoses. Highly aggressive species like mucormycosis, Scedosporium, and Fusarium are becoming more common and demonstrate high levels of resistance to antifungals. Common risk factors include prior colonization, neutropenia, lymphopenia, immunosuppression, viral coinfections such as CMV and human herpes virus 6 (HHV6), diabetes, and use of antimicrobial agents [54]. In the early post-transplant period, Candida infections typically present as candidemia, superinfection of esophageal lesions due to herpes simplex virus (HSV), CMV, as well as infections of tracheal anastomoses. One dreaded manifestation is mycotic aneurysm formed by vascular anastomotic infections that can rupture. Aspergillus is a common colonizer with $>25 \%$ rate of colonization in lung transplant recipients. Invasive aspergillosis accounts for $6 \%$ of infections and includes tracheobronchitis, bronchial anastomotic infections, and invasive pulmonary $(32 \%)$ and disseminated $(22 \%)$ infections. The rates are higher in patients with cystic fibrosis and single lung recipients [55].

Clostridium difficile (C. difficile) affects up to $30 \%$ of solid organ transplant (SOT) recipients with the highest incidence in lung recipients (7-31\%) [56]. Risk factors unique to SOT recipients are use of antithymocyte globulin, hypogammaglobulinemia, re-transplantation, and the type of organ transplanted [56]. Diagnosis and treatment of $C$. difficile infection in transplant recipients present unique challenges and require a multidisciplinary approach.

\section{Bleeding and thromboembolic events}

There is increased incidence of bleeding and thromboembolic events in the immediate post-transplant period. In patients requiring $\mathrm{ECMO}$ or $\mathrm{CPB}$, increased incidence of bleeding is observed due to the need for full systemic anticoagulation $[8$, $57,58]$. One study described a $12.9 \%$ incidence of hemothorax occurring on average 9-days post-transplant, with delayed hemothorax occurring in patients on anticoagulation. In some 
cases, re-thoracotomy is needed due to severe bleeding [59]. At the Ochsner Multi-Organ Transplant Institute, 5 out of 208 patients who required $\mathrm{CPB}$ required re-explorations for bleeding occurring in the perioperative period [60].

Venous thromboembolism (VTE) is a well-known complication of lung transplantation [61-65] and is associated with lower survival rates among lung transplant recipients [66]. The reported incidence of VTE in the immediate postoperative period, however, is variable, with some reporting an incidence of $5-15 \%$ for pulmonary embolism (PE) and $20-45 \%$ for deep vein thrombosis (DVT) [66-68]. A single-center review of lung transplant recipients described a median interval to diagnosis of upper extremity DVT of 8 days, that of lower extremity DVT of 5.4 months, and that of PE of 7.5 months [66]. Intraoperative $\mathrm{CPB}$ or ECMO was associated with lower incidence of PE. All PEs observed were in the allograft. Patients who had developed VTE within the first 5 days postoperatively had higher risk of later developing VTE; chemical prophylaxis for VTE was noted to be a modifiable risk factor [68]. All patients with PE had evidence of DVT at some point during their postoperative course. Patients with lower extremity DVT are twice as likely to die than those without lower extremity DVT [66].

Treatment varies from full systemic anticoagulation with enoxaparin, warfarin, or heparin, to inferior vena cava filter placement, embolectomy, and surgical revision of venous anastomosis.

\section{Renal dysfunction}

Renal dysfunction in lung transplant patients is associated with worse outcomes and increased risk for death [69, 70]. Preoperative risk factors include increase in systolic blood pressure, decline in renal function, and a history of pulmonary hypertension [71]. Postoperative risk factors include irregularity in hemodynamics and use of nephrotoxic immunosuppressants like cyclosporine, a calcineurin inhibitor [72]. Cyclosporine-induced acute nephrotoxicity is caused by the constriction of afferent arterioles, which is presumed to be due to renin-angiotensin activation, sympathetic nervous system stimulation, increased endothelin- 1 and thromboxane production, and nitric oxide suppression [73]. While acute nephrotoxicity of cyclosporine is dose-dependent and reversible upon discontinuation, chronic nephrotoxicity - caused by a change in renal architecture including atrophy of renal tubules, glomerulosclerosis, and tubulointerstitial fibrosis - can lead to permanent damage [73].

The use of tacrolimus instead of cyclosporine and basiliximab induction therapy can be protective against acute kidney injury (AKI) [74]. However, hemolytic uremic syndrome (HUS) can occur with use of cyclosporine or tacrolimus [75, 76]. Laboratory results would show elevated lactate dehydrogenase, thrombocytopenia, and signs of azotemia and schistocytes on peripheral blood smear [77].

AKI can occur in the early post-lung transplant period [70, 78]. It is associated with increased short- and long-term mortality [78]. In one retrospective study, $64.5 \%$ of the patients developed AKI in the first 2 weeks post-transplant [70]. Patients with AKI had significantly diminished survival rates than those without [74]. Patients with AKI were also kept on invasive mechanical ventilator longer, received more tracheostomies, had higher need for ECMO, and required vasoactive administration for longer periods of time compared those without [74]. In another retrospective cohort study, $68.8 \%$ of lung transplant patients developed AKI within the first week after transplant, $51.3 \%$ of which had early recovery [79]. Those with transient AKI experienced fewer complications such as tracheostomy, lower incidents of chronic kidney disease (CKD) at 1- and 3-years post-transplant, and shorter need for invasive mechanical ventilation [79]. Higher body mass index (BMI), use of immunosuppressant drugs such as cyclosporine, longer duration of mechanical ventilator, and CKD stages II and III are some of the factors associated with persistent AKI [79].

AKI increases the chance of developing CKD after lung transplant [70]. The incidence of CKD at 1-year post-lung transplant was reported as $5.8 \%$ in those recipients who did not develop AKI in the immediate post-transplant period. This incidence increased to $12.8-24.5 \%$ in those who developed some degree of AKI [70]. CKD development among nonrenal transplant recipients is associated with a 4-fold increase in the risk of death [69].

\section{Gastrointestinal complications}

Gastrointestinal (GI) complications after lung transplantation are common and carry significant morbidity and mortality [80]. GI complications range from nausea, vomiting, gastritis, and diarrhea, to emergencies like bowel perforation or bleeding from the GI tract [81]. The rate of GI complications in lung transplant recipients can be as high as $50 \%$ or more [80, 81]. The majority of complications are associated with immunosuppressive medications and manifest as biliary tract disease - at times requiring cholecystectomy - opportunistic infections, mucosal injury, viscus perforations, pancreatitis, or malignancies [81-83].

There is high incidence of motility disorders after lung transplant [84]. Anatomical proximity and hemodynamic changes can cause injury to the vagus nerve during surgery, resulting in delayed gastroparesis and bowel obstruction [84, 85]. C. difficile colitis and CMV gastroenteritis are also common [86].

There is a high preoperative prevalence of gastroesophageal reflux disease (GERD) in end-stage lung disease patients 
[80,87, 88], and lung transplantation may increase the risk of GERD and peptic ulcer disease [88]. Several studies showed a link between GERD and aspiration that may result in the development of BOS $[88,89]$.

Serious GI complications can occur that require surgical management. A study reported that over a period of 19 months, about $10 \%$ of recipients with acute abdomen needed surgical intervention [83]. Rare complications like superior mesenteric artery syndrome and pneumatosis intestinalis were are also reported [86].

\section{Neurological complications}

A study of 700 lung transplant recipients found a $9.2 \%$ incidence of neurologic complications in the first 2-weeks post-transplantation including stroke and metabolic encephalopathy [90-92]. Patients with neurologic complications have an increased 90-day mortality compared to lung transplant recipients without [92]. Approximately 5-10\% of lung transplant recipients suffer from stroke [93, 94]. In a large retrospective study $(n=759), 90$-day mortality rate in patients with neurological complications was $15 \%$, versus $4 \%$ among recipients who did not develop neurological complications [92]. Recipients with neurological complications had a prolonged length of stay and increased duration of mechanical ventilation $[92,93]$. Lung transplant recipients with suspected stroke should undergo timely imaging with $\mathrm{CT}$ or MRI of the brain with angiography to identify large vessel occlusion. A transthoracic or transesophageal echocardiography should also be done if cardioembolic stroke is suspected. As with standard of care, secondary stroke prevention includes consideration for antiplatelet therapy or anticoagulation.

Severe hyperammonemia has been described with a $1 \%$ incident rate 2-weeks post-transplant [90]. Treatment of hyperammonemia includes dialysis, reduction of immunosuppression, protein restriction, and use of empiric fluoroquinolone or macrolide to eradicate urea-splitting organisms [90].

Posterior reversible encephalopathy (PRES) is rare after lung transplantation associated with calcineurin inhibitor use, with an incidence of about $1.9 \%$ [95]. Patients usually present with headache, altered mental status, visual disturbances, focal neurological deficits, and seizures. Recipients with PRES may require temporary discontinuation of calcineurin inhibitor use and tight blood pressure control [96]. Lung transplant recipients can also have seizures due to stroke, medication toxicity, PRES, and hyperammonemia [97]. It is crucial to initiate antiepileptic medications while managing underlying etiology of seizures.

\section{Musculoskeletal and neuropathic complications}

Several studies show a significant reduction in skeletal muscle strength and function including respiratory and limb muscles in lung transplant recipients $[98,99]$. Critical illness myopathy or neuropathy is a persistently observed complication in lung transplant recipients, unrelated to the pre-transplant diagnosis and the type of surgery $[98,100]$. Reduced muscle mass and strength are consistently seen in patients with end-stage lung disease. In a systemic review, quadriceps muscle weakness was found to be further decreased in the early postoperative phase $[98,99]$. Possible etiology includes reduced postoperative activity and deconditioning, corticosteroid-induced muscle damage, critical illness-related neuropathy or myopathy, therapy with calcineurin inhibitor, and impaired skeletal muscle oxidative capacity $[34,99]$. Duration of mechanical ventilation, use of sedatives and steroids, longer duration of immobilization, and inactivity are significantly related to ICUacquired weakness [101].

Aggressive pre-transplant and early post-transplant rehabilitation is crucial to maintain functional status [98, 99]. A randomized controlled trial noted a significant improvement in quadriceps muscle force and functional capacity in uncomplicated lung transplant recipients with a 3-month rehabilitation program [102]. Identifying risk factors, early mobilization in ICU, and frequent bedside neuromuscular examination can help alleviate the impact of critical illness-related weakness.

\section{Local wound complications after lung transplant}

Wound dehiscence can occur even after careful suturing and closure, and is a potential complication in lung transplantation, especially in patients with a clamshell incision [103-105]. Wound dehiscence is commonly seen in the first week after surgery, but may present later due to poor wound healing. Mechanical factors including continuous motion and tension in the thoracic region, and individual factors including older age, hemodynamic stability, wound infection, and underlying comorbidities are associated with increased wound dehiscence [106]. Various pathogens that are associated with nosocomial infections such as Pseudomonas aeruginosa, S. aureus, Mycoplasma hominis, and Candida are associated with the wound infections [107-109]. However, infection of the skin and soft tissues around the surgical site is not very common.

\section{Cardiovascular complications}

Atrial arrhythmias including atrial flutter, atrial fibrillation, and supraventricular tachycardia (SVT) are frequently encountered in the early postoperative period after lung transplantation [34]. Incidence is high, occurring in $25-35 \%$ of recipients. Age, pre-transplant diagnosis of idiopathic pulmonary fibrosis, left atrial enlargement, diastolic dysfunction, and coronary artery disease (CAD) are major risk factors for 
developing atrial fibrillation, while age, right ventricular enlargement, elevated right atrial pressure, and right ventricular dysfunction were predictors of atrial flutter or SVT [110]. Rate control is the first-line therapy; however, many required a combination of rate control and anti-arrhythmic medications, with a study showing dofetilide/ibutilide to be a helpful addition [111]. Cardioversion may be indicated if hemodynamic instability presents.

Shock is common after lung transplantation generally due to postop vasoplegia. Vasoplegia is characterized by the pathological loss of vasomotor tone refractory to fluid resuscitation or vasopressors, normal to high cardiac index, and hypotension. It occurs at high rates in the early post-transplant period and contributes to significant morbidity. Manikavasagar et al. found 32\% incidence of vasoplegia and suggest the potential involvement of oxidative stress in the development of this syndrome [112]. Use of $\mathrm{CPB}$ has been implicated in vasoplegia due to immunogenic effect. Anecdotally, use of methylene blue in CPB-induced vasoplegia has been effective in increasing mean arterial pressure intraoperatively [113].

Myocardial infarction incidence in lung transplant recipients is not fully described in current literature. It often occurs late after transplantation and can be caused by air embolism from bronchial-coronary fistula [114] or arterial thrombosis related to inflammation and immunosuppressive therapy [115].

Other rare causes of post-lung transplant cardiac complications include cardiac tamponade secondary to pneumopericardium [116, 117], and pericardial constriction causing cardiac diastolic dysfunction - of which only 2 cases have been reported post-transplantation [118].

\section{Heart-lung transplantation}

Combined heart-lung transplantation developed in parallel with heart transplantation and lung transplantation, with the first operation performed in 1981 [119] and growth in the 1980s driven by improvements in surgical techniques and immunosuppressive therapy. However, heart-lung transplants have become much less common in the recent era, with ISHLT reporting a peak of 263 cases in 1989 and 62 cases in 2017 [120]. This decrease has been driven by growth in isolated lung and heart transplantation, better perioperative management of isolated lung and heart transplant recipients, and optimizing use of scarce donor organs.

Heart-lung transplantation is performed by anastomosis of the donor and recipient trachea, ascending aorta, and superior and inferior vena cavae. These bronchial and vascular structures are susceptible to the same technical complications as in isolated lung transplantation, but at a lower frequency due to their larger size.

Lung transplants are more susceptible to dysfunction than heart transplants, and this experience carries into the population with combined heart-lung transplants. Additionally, there is some evidence to support that combined heart-lung transplantation is protective of dysfunction of both allografts [121].

\section{Conclusion}

The medical and surgical community is tasked with the great challenge of caring for lung transplant recipients. There have been immeasurable improvements since the first human lung transplant was performed in 1963. With ever-changing innovations in treatment strategies, however, decisions should be informed by the development of guidelines and consensus statements. A multidisciplinary approach which leverages specialists from surgical, medical, and rehabilitation services is key to improving post-lung transplant survival.

Abbreviations AKI, Acute kidney injury; AMR, Antibody-mediated rejection; BOS, Bronchiolitis obliterans syndrome; BMI, Body mass index; C. difficile, Clostridium difficile; CAD, Coronary artery disease; CAV, Cardiac allograft vasculopathy; CKD, Chronic kidney injury; CMV, Cytomegalovirus; CPB, Cardiopulmonary bypass; CT, Computed tomography; D+, CMV-seropositive donor; DVT, Deep vein thrombosis; ECMO, Extracorporeal membrane oxygenation; FEV1, Forced expiratory volume in $1 \mathrm{~s}$; GERD, Gastroesophageal reflux disease; GI, Gastrointestinal; HHV6, Human herpes virus 6; HLA, Human leukocyte antigen; HSV, Herpes simplex virus; HUS, Hemolytic uremic syndrome; ICU, Intensive care unit; ISHLT, International Society for Heart and Lung Transplantation; IVIG, Intravenous immunoglobulin; MRI, Magnetic resonance imaging; MRSA, Methicillin-resistant Staphylococcus aureus; PE, Pulmonary embolism; PGD, Primary graft dysfunction; PRA, Panel-reactive antibody; PRES, Posterior reversible encephalopathy; R+, CMV-seropositive recipient; SOT, Solid organ transplant; SVT, Supraventricular tachycardia; V/Q, Ventilation-perfusion; VTE, Venous thromboembolism

Funding None.

\section{Declarations}

Research involving human participants and/or animals Not applicable as the scientific information presented in the paper does not fall into category of clinical trial or usage of experimental modalities.

Informed consent Not applicable as this is a literature review and no subjects were involved.

Conflict of interest The authors declare no competing interests.

\section{References}

1. Ahmad S, Shlobin OA, Nathan SD. Pulmonary complications of lung transplantation. Chest. 2011;139:402-11. 
2. Altun GT, Arslantas MK, Cinel I. Primary graft dysfunction after lung transplantation. Turk J Anaesthesiol Reanim. 2015;43:418 23.

3. Cantu E, Lederer DJ, Meyer K, et al. Gene set enrichment analysis identifies key innate immune pathways in primary graft dysfunction after lung transplantation. Am J Transplant. 2013;13:1898904.

4. Diamond JM, Lee JC, Kawut SM, et al. Clinical risk factors for primary graft dysfunction after lung transplantation. Am J Respir Crit Care Med. 2013;187:527-34.

5. Oto T, Excell L, Griffiths AP, Levvey BJ, Snell GI. The implications of pulmonary embolism in a multiorgan donor for subsequent pulmonary, renal, and cardiac transplantation. J Heart Lung Transplant. 2008;27:78-85.

6. Christie JD, Carby M, Bag R, Corris P, Hertz M, Weill D. Report of the ISHLT Working Group on primary lung graft dysfunction part II: definition. A consensus statement of the International Society for Heart and Lung Transplantation. J Heart Lung Transplant. 2005;24:1454-9.

7. Christie JD, Bellamy S, Ware LB, et al. Construct validity of the definition of primary graft dysfunction after lung transplantation. J Heart Lung Transplant. 2010;29:1231-9.

8. Fischer S, Bohn D, Rycus P, et al. Extracorporeal membrane oxygenation for primary graft dysfunction after lung transplantation: analysis of the Extracorporeal Life Support Organization (ELSO) registry. J Heart Lung Transplant. 2007;26:472-7.

9. Castleberry AW, Hartwig MG, Whitson BA. Extracorporeal membrane oxygenation post lung transplantation. Curr Opin Organ Transplant. 2013;18:524-30.

10. Nguyen DQ, Kulick DM, Bolman RM III, Dunitz JM, Hertz MI, Park SJ. Temporary ECMO support following lung and heart-lung transplantation. J Heart Lung Transplant. 2000;19:313-6.

11. Mahajan AK, Folch E, Khandhar SJ, et al. The diagnosis and management of airway complications following lung transplantation. Chest. 2017;152:627-38.

12. Murthy SC, Blackstone EH, Gildea TR, et al. Impact of anastomotic airway complications after lung transplantation. Ann Thorac Surg. 2007;84:401-9.e1-4.

13. Yserbyt J, Dooms C, Vos R, Dupont LJ, van Raemdonck DE, Verleden GM. Anastomotic airway complications after lung transplantation: risk factors, treatment modalities and outcome-a single-centre experience. Eur J Cardiothorac Surg. 2016;49:e1-8.

14. Mulligan MS. Endoscopic management of airway complications after lung transplantation. Chest Surg Clin N Am. 2001;11:90715.

15. Santacruz JF, Mehta AC. Airway complications and management after lung transplantation: ischemia, dehiscence, and stenosis. Proc Am Thorac Soc. 2009;6:79-93.

16. Dunlap DG, Ma KC, DiBardino D. Airway complications and endoscopic management after lung transplantation. Curr Pulmonol Rep. 2020;9:181-9.

17. Patoir A, Luchez A, Tiffet $\mathrm{O}$, et al. Airway complications after lung transplantation: benefit of a conservative bronchoscopy strategy. J Thorac Dis. 2020;12:2625-34.

18. Ma KC, Li M, Haas AR, Lanfranco AR, Moon EK, DiBardino DM. Efficacy and safety of airway stenting to treat anastomotic complications after lung transplant: a cohort study. J Thorac Dis. 2020;12:3539-48.

19. Backer E, Dincer EH, Keenan JC, Diaz-Gutierrez I, Cho RJ. Successful treatment of airway dehiscence in a lung transplant patient with radiofrequency ablation. J Bronchology Interv Pulmonol. 2020;27:e56-9.

20. Schweiger T, Nenekidis I, Stadler JE, et al. Single running suture technique is associated with low rate of bronchial complications after lung transplantation. J Thorac Cardiovasc Surg. 2020;160: 1099-1108.e3.
21. Batra K, Chamarthy MR, Reddick M, Roda MS, Wait M, Kalva SP. Diagnosis and interventions of vascular complications in lung transplant. Cardiovasc Diagn Ther. 2018;8:378-86.

22. Siddique A, Bose AK, Ozalp F, et al. Vascular anastomotic complications in lung transplantation: a single institution's experience. Interact Cardiovasc Thorac Surg. 2013;17:625-31.

23. Hausmann D, Daniel WG, Mügge A, et al. Imaging of pulmonary artery and vein anastomoses by transesophageal echocardiography after lung transplantation. Circulation. 1992;86:II251-8.

24. Najafizadeh K, Daneshvar A, Dezfouli AA, et al. Pulmonary artery stenosis shortly after lung transplantation: successful balloon dilation and stent insertion in one case. Ann Transplant. 2009;14: $52-5$.

25. Maziak DE, Maurer JR, Kesten S. Diaphragmatic paralysis: a complication of lung transplantation. Ann Thorac Surg. 1996;61: 170-3.

26. Sano Y, Oto T, Toyooka S, Yamane M, Okazaki M, Date H. Phrenic nerve paralysis following lung transplantation. Kyobu Geka. 2007;60:993-7.

27. Shigemura N, D'Cunha J, Bhama J, et al. Diaphragm dysfunction following lung transplantation: the largest single-center experience. Chest. 2013;144:1009A.

28. LoMauro A, Righi I, Privitera E, et al. The impaired diaphragmatic function after bilateral lung transplantation: a multifactorial longitudinal study. J Heart Lung Transplant. 2020;39:795-804.

29. Xu Y, Qing Q, Liang M, et al. Diaphragm electromyography guidance for a lung transplant recipient with difficult weaning from mechanical ventilation: a case report. Medicine (Baltimore). 2018;97:e10989.

30. Kovzel M, Ali JM, Aresu G, Catarino P. Spontaneous diaphragmatic rupture as a complication following lung transplantation. Am J Transplant. 2020;20:1744-7.

31. Ferrer J, Rolden J, Roman A, et al. Acute and chronic pleural complications in lung transplantation. J Heart Lung Transplant. 2003;22:1217-25.

32. Herridge MS, de Hoyos AL, Chaparro C, Winton TL, Kesten S, Maurer JR. Pleural complications in lung transplant recipients. J Thorac Cardiovasc Surg. 1995;110:22-6.

33. Arndt A, Boffa DJ. Pleural space complications associated with lung transplantation. Thorac Surg Clin. 2015;25:87-95.

34. Garrido, G. and G.S. Dhillon, Medical course and complications after lung transplantation, in Psychosocial care of end-stage orgen disease and transplant patients, Y. Sher and J.R. Maldonado, Editors. 2018, Springer International Publishing: Cham p 279288.

35. Jacob S, Meneses A, Landolfo K, et al. Incidence, management, and outcomes of chylothorax after lung transplantation: a singlecenter experience. Cureus. 2019;11:e5190.

36. Navarro JC, de Aguiar Quevedo K, Franch NM, Cuesta JCP, Sempere FJV, Alarcón JP. Complications after lung transplantation in chronic obstructive pulmonary disease. Med Clin (Barc). 2013;140:385-9.

37. Hong A, King CS, Brown AWW. Hemothorax following lung transplantation: incidence, risk factors, and effect on morbidity and mortality. Multidiscip Respir Med. 2016;11:40.

38. Ferrer J, Rodriguez E, Roman A. Factors related to postoperative mortality in lung transplantation for emphysema. Transplant Proc. 2007;39:3317-22.

39. Nunley DR, Grgurich WF, Keenan RJ, Dauber JH. Empyema complicating successful lung transplantation. Chest. 1999;115: 1312-5.

40. Wahidi MM, Willner DA, Snyder LD, Hardison JL, Chia JY, Palmer SM. Diagnosis and outcome of early pleural space infection following lung transplantation. Chest. 2009;135:484-91.

41. Judson MA, Sahn SA, Hahn AB. Origin of pleural cells after lung transplantation: from donor or recipient? Chest. 1997;112:426-9. 
42. Chambers DC, Yusen RD, Cherikh WS, et al. The Registry of the International Society for Heart and Lung Transplantation: thirtyfourth adult lung and heart-lung transplantation report-2017; focus theme: allograft ischemic time. J Heart Lung Transplant. 2017;36: 1047-59.

43. Trulock EP, Christie JD, Edwards LB, et al. Registry of the International Society for Heart and Lung Transplantation: twenty-fourth official adult lung and heart-lung transplantation report-2007. J Heart Lung Transplant. 2007;26:782-95.

44. Valapour M, Lehr CJ, Skeans MA, et al. OPTN/SRTR 2016 annual data report: lung. Am J Transplant. 2018;18:363-433.

45. Mangi AA, Mason DP, Nowicki ER, et al. Predictors of acute rejection after lung transplantation. Ann Thorac Surg. 2011;91: 1754-62.

46. Kumar D, Erdman D, Keshavjee S, et al. Clinical impact of community-acquired respiratory viruses on bronchiolitis obliterans after lung transplant. Am J Transplant. 2005;5:2031-6.

47. Parulekar AD, Kao CC. Detection, classification, and management of rejection after lung transplantation. J Thorac Dis. 2019;11:S1732-9.

48. Levine DJ, Glanville AR, Aboyoun C, et al. Antibody-mediated rejection of the lung: a consensus report of the International Society for Heart and Lung Transplantation. J Heart Lung Transplant. 2016;35:397-406.

49. Witt CA, Gaut JP, Yusen RD, et al. Acute antibody-mediated rejection after lung transplantation. J Heart Lung Transplant. 2013;32:1034-40.

50. Ensor CR, Yousem SA, Marrari M, et al. Proteasome inhibitor carfilzomib-based therapy for antibody-mediated rejection of the pulmonary allograft: use and short-term findings. Am J Transplant. 2017;17:1380-8.

51. Fishman JA. Infection in organ transplantation. Am J Transplant. 2017:17:856-79.

52. Kotton CN, Kumar D, Caliendo AM, et al. Updated international consensus guidelines on the management of cytomegalovirus in solid-organ transplantation. Transplantation. 2013;96:333-60.

53. Razonable RR, Humar A. Cytomegalovirus in solid organ transplantation. Am J Transplant. 2013;13:93-106.

54. Pappas PG, Silveira FP. Candida in solid organ transplant recipients. Am J Transplant. 2009;9:S173-9.

55. Patterson TF, Thompson GR 3rd, Denning DW, et al. Practice guidelines for the diagnosis and management of aspergillosis: 2016 update by the Infectious Diseases Society of America. Clin Infect Dis. 2016;63:e1-e60.

56. Bruminhent J, Cawcutt KA, Thongprayoon C, Petterson TM, Kremers WK, Razonable RR. Epidemiology, risk factors, and outcome of Clostridium difficile infection in heart and heart-lung transplant recipients. Clin Transplant. 2017;31. https://doi.org/10. 1111/ctr.12968.

57. Hartwig MG, Appel JZ 3rd, Cantu E 3rd, et al. Improved results treating lung allograft failure with venovenous extracorporeal membrane oxygenation. Ann Thorac Surg. 2005;80:1872-9.

58. Mason DP, Boffa DJ, Murthy SC, et al. Extended use of extracorporeal membrane oxygenation after lung transplantation. J Thorac Cardiovasc Surg. 2006;132:954-60.

59. Pereszlenyi A, Lang G, Steltzer H, et al. Bilateral lung transplantation with intra- and postoperatively prolonged ECMO support in patients with pulmonary hypertension. Eur J Cardiothorac Surg. 2002;21:858-63.

60. Bates M, Factor M, Parrino PE, et al. Lung Transplantation and the routine use of cardiopulmonary bypass and median sternotomy: experience at the Ochsner Multi-Organ Transplant Institute. Ochsner J. 2017;17:38-41.

61. Burns KEA, Iacono AT. Incidence of clinically unsuspected pulmonary embolism in mechanically ventilated lung transplant recipients. Transplantation. 2003;76:964-8.
62. Burns KEA, Iacono AT. Pulmonary embolism on postmortem examination: an under-recognized complication in lungtransplant recipients? Transplantation. 2004;77:692-8.

63. Izbicki G, Bairey O, Shitrit D, Lahav J, Kramer MR. Increased thromboembolic events after lung transplantation. Chest. 2006;129:412-6.

64. Kroshus TJ, Kshettry VR, Hertz MI, Bolman RM 3rd. Deep venous thrombosis and pulmonary embolism after lung transplantation. J Thorac Cardiovasc Surg. 1995;110:540-4.

65. Yegen HA, Lederer DJ, Barr RG, et al. Risk factors for venous thromboembolism after lung transplantation. Chest. 2007;132: 547-53.

66. Evans CF, Iacono AT, Sanchez PG, et al. Venous thromboembolic complications of lung transplantation: A contemporary singleinstitution review. Ann Thorac Surg. 2015;100:2033-9.

67. Ribeiro Neto ML, Budev M, Culver DA, et al. Venous thromboembolism after adult lung transplantation: a frequent event associated with lower survival. Transplantation. 2018;102:681-7.

68. Zheng M, Yousef I, McEldrew J, et al. Incidence and potentially modifiable risk factors for venous thromboemblism post lung transplant. J Heart Lung Transplant. 2020;39:S316.

69. Ojo AO, Held PJ, Port FK, et al. Chronic renal failure after transplantation of a nonrenal organ. N Engl J Med. 2003;349:931-40.

70. Wehbe E, Brock R, Budev M, et al. Short-term and long-term outcomes of acute kidney injury after lung transplantation. J Heart Lung Transplant. 2012;31:244-51.

71. Esposito C, de Mauri A, Vitulo P, et al. Risk factors for chronic renal dysfunction in lung transplant recipients. Transplantation. 2007;84:1701-3.

72. Puttarajappa CM, Bernardo JF, Kellum JA. Renal complications following lung transplantation and heart transplantation. Crit Care Clin. 2019;35:61-73.

73. Campistol JM, Sacks SH. Mechanisms of nephrotoxicity. Transplantation. 2000;69:SS5-S10.

74. Bennett D, Fossi A, Marchetti L. Postoperative acute kidney injury in lung transplant recipients. Interact Cardiovasc Thorac Surg. 2019;28:929-35.

75. Galli FC, Damon LE, Tomlanovich SJ, Keith F, Chatterjee K, DeMarco T. Cyclosporine-induced hemolytic uremic syndrome in a heart transplant recipient. J Heart Lung Transplant. 1993;12: 440-4.

76. Walder B, Ricou B, Suter PM. Tacrolimus (FK 506)-induced hemolytic uremic syndrome after heart transplantation. J Heart Lung Transplant. 1998;17:1004-6.

77. Kotloff RM, Ahya VN. Medical complications of lung transplantation. Eur Respir J. 2004;23:334-42.

78. Atchade E, Barour S, Tran-Dinh A, et al. Acute kidney injury after lung transplantation: perioperative risk factors and outcome. Transplant Proc. 2020;52:967-76.

79. Fidalgo P, Ahmed M, Meyer SR, et al. Association between transient acute kidney injury and morbidity and mortality after lung transplantation: a retrospective cohort study. J Crit Care. 2014;29: 1028-34.

80. Paul S, Escareno CE, Clancy K, Jaklitsch MT, Bueno R, Lautz DB. Gastrointestinal complications after lung transplantation. J Heart Lung Transplant. 2009;28:475-9.

81. Bravo C, Gispert P, Borro JM, et al. Prevalence and management of gastrointestinal complications in lung transplant patients: MITOS study group. Transplant Proc. 2007;39:2409-2412.

82. Helderman JH, Goral S. Gastrointestinal complications of transplant immunosuppression. J Am Soc Nephrol. 2002;13:277-87.

83. Hoekstra H, Hawkins K, de Boer WJ, Rottier K, W van der Bij W. Gastrointestinal complications in lung transplant survivors that require surgical intervention. Br J Surg. 2001;88:433-8. 
84. Au J, Hawkins T, Venables C, et al. Upper gastrointestinal dysmotility in heart-lung transplant recipients. Ann Thorac Surg. 1993;55:94-7.

85. Berkowitz N, Schulman LL, McGregor C, Markowitz D. Gastroparesis after lung transplantation: potential role in postoperative respiratory complications. Chest. 1995;108:1602-7.

86. Kayawake H, Chen-Yoshikawa TF, Motoyama H, et al. Gastrointestinal complications after lung transplantation in Japanese patients. Surg Today. 2018;48:883-90.

87. Raviv Y, D’Ovidio F, Pierre A, et al. Prevalence of gastroparesis before and after lung transplantation and its association with lung allograft outcomes. Clin Transplant. 2012;26:133-42.

88. Hadjiliadis D, Duane Davis R, Steele MP, et al. Gastroesophageal reflux disease in lung transplant recipients. Clin Transplant. 2003;17:363-368.

89. Palmer SM, Miralles AP, Howell DN, Brazer SR, Tapson VF, Davis RD. Gastroesophageal reflux as a reversible cause of allograft dysfunction after lung transplantation. Chest. 2000;118: 1214-7.

90. Chen C, Bain KB, Iuppa JA, et al. Hyperammonemia syndrome after lung transplantation: a single center experience. Transplantation. 2016;100:678-84.

91. Kao CC, Parulekar AD. Postoperative management of lung transplant recipients. J Thorac Dis. 2019;11:S1782-8.

92. Shigemura N, Sclabassi RJ, Bhama JK, et al. Early major neurologic complications after lung transplantation: incidence, risk factors, and outcome. Transplantation. 2013;95:866-71.

93. Gamez J, Salvado M, Martinez-de La Ossa A, et al. Influence of early neurological complications on clinical outcome following lung transplant. PLoS One. 2017;12:e174092.

94. Mateen FJ, Dierkhising RA, Rabinstein AA, van de Beek D, Wijdicks EFM. Neurological complications following adult lung transplantation. Am J Transplant. 2010;10:908-14.

95. Yamagishi H, Chen-Yoshikawa TF, Date H. Basiliximab for posterior reversible encephalopathy syndrome after lung transplantation. Eur J Cardiothorac Surg. 2017;52:823-4.

96. Rosso L, Nosotti M, Mendogni P, et al. Lung transplantation and posterior reversible encephalopathy syndrome: a case series. Transplant Proc. 2012;44:2022-5.

97. Vaughn BV, Ali II, Olivier KN, et al. Seizures in lung transplant recipients. Epilepsia. 1996;37:1175-9.

98. Lands LC, Smountas AA, Mesiano G, et al. Maximal exercise capacity and peripheral skeletal muscle function following lung transplantation. J Heart Lung Transplant. 1999;18:113-20.

99. Maury G, Langer D, Verleden G. Skeletal muscle force and functional exercise tolerance before and after lung transplantation: a cohort study. Am J Transplant. 2008;8:1275-81.

100. Pinet C, Scillia P, Cassart M, et al. Preferential reduction of quadriceps over respiratory muscle strength and bulk after lung transplantation for cystic fibrosis. Thorax. 2004;59:783-9.

101. Schweickert WD, Hall J. ICU-acquired weakness. Chest. 2007;131:1541-9.

102. Langer D, Burtin C, Schepers L, et al. Exercise training after lung transplantation improves participation in daily activity: a randomized controlled trial. Am J Transplant. 2012;12:1584-92.

103. Paradela M, Gonzalez D, Parente I, et al. Surgical risk factors associated with lung transplantation. Transplant Proc. 2009;41: 2218-20.

104. Arndt G, Granger R, Glanville A, Malouf M. Clamshell incision vs. sternal-sparing incision in lung transplantation. J Heart Lung Transplant. 2013;32:S265.
105. López ER, Madueno FC, Garcia FJG, et al. Thoracotomy wound dehiscence after lung transplant is an effective surgical solution: a case report. Transplant Proc. 2020;52:584-6.

106. Riou J-PA, Cohen JR, Johnson H Jr. Factors influencing wound dehiscence. Am J Surg. 1992;163:324-30.

107. Routledge T, Saeb-Parsy K, Fiona Murphy RN, Ritchie AJ. The use of vacuum-assisted closure in the treatment of post-transplant wound infections: a case series. J Heart Lung Transplant.2005;24: 1444. e15-1444. e16.

108. Mossad S, Rehm SJ, Tomford JW, et al. Sternotomy infection with Mycoplasma hominis: a cause of "culture negative" wound infection. J Cardiovasc Surg. 1996;37:505-9.

109. Hopkins PM, Winlaw DS, Chhajed PN, et al. Mycoplasma hominis infection in heart and lung transplantation. J Heart Lung Transplant. 2002;21:1225-9.

110. Orrego CM, Cordero-Reyes AM, Estep JD, et al. Atrial arrhythmias after lung transplant: underlying mechanisms, risk factors, and prognosis. J Heart Lung Transplant. 2014;33:734-40.

111. Raghavan D, Gao A, Ahn C, et al. Contemporary analysis of incidence of post-operative atrial fibrillation, its predictors, and association with clinical outcomes in lung transplantation. J Heart Lung Transplant. 2015;34:563-70.

112. Manikavasagar V, Romano R, Aw TC, de Waal E, Simon A, Marczin N. Early post-operative vasoplegia in lung transplantation. J Cardiothorac Vasc Anesth. 2019;33:S88.

113. Carley M, Schaff J, Lai T, Poppers J. Methylene blue for vasoplegia when on cardiopulmonary bypass during doublelung transplantation. A A Case Rep. 2015;5:127-30.

114. Johnston SL, Halabi S, Cohoon K, Alex C, Hutchens K, Leya F. Stroke and myocardial infarction as late complications of lung transplantation. J Heart Lung Transplant. 2007;26:1065-8.

115. Parsa SA, Khaheshi I, Dousti A, Naghashzadeh F, Ataeinia B. STelevation myocardial infarction 33 days after lung transplant in a patient with non-significant CAD before transplantation: a case report. J Clin Diagn Res. 2016;10:OD23-4.

116. Lasocki S, Castier Y, Geffroy A, et al. Early cardiac tamponade due to tension pneumopericardium after bilateral lung transplantation. J Heart Lung Transplant. 2007;26:1069-71.

117. Navas B, Cobos MJ, Vaquero JM, Santos F, Cosano A. Cardiac tamponade secondary to pneumopericardium after lung transplantation: a case report. Transplant Proc. 2008;40:3123-5.

118. Afshar K, Cunningham MJ, Barbers RG, McFadden PM. Pericardial constriction after lung transplantation. Ann Thorac Surg. 2010;90:1361-3.

119. Reitz BA, Wallwork JL, Hunt SA, et al. Heart-lung transplantation: successful therapy for patients with pulmonary vascular disease. N Engl J Med. 1982;306:557-64.

120. Khush KK, Cherikh WS, Chambers DC, et al. The International Thoracic Organ Transplant Registry of the International Society for Heart and Lung Transplantation: thirty-sixth adult heart transplantation report - 2019; focus theme: donor and recipient size match. J Heart Lung Transplant. 2019;38:1056-66.

121. Pinderski LJ, Kirklin JK, McGiffin D, et al. Multi-organ transplantation: is there a protective effect against acute and chronic rejection? J Heart Lung Transplant. 2005;24:1828-33.

Publisher's note Springer Nature remains neutral with regard to jurisdictional claims in published maps and institutional affiliations. 